\title{
Social Cohesion and Development
}

\section{Social Cohesion and Development $=$ \\ Efoprmaia Enernjovix Imecuponan

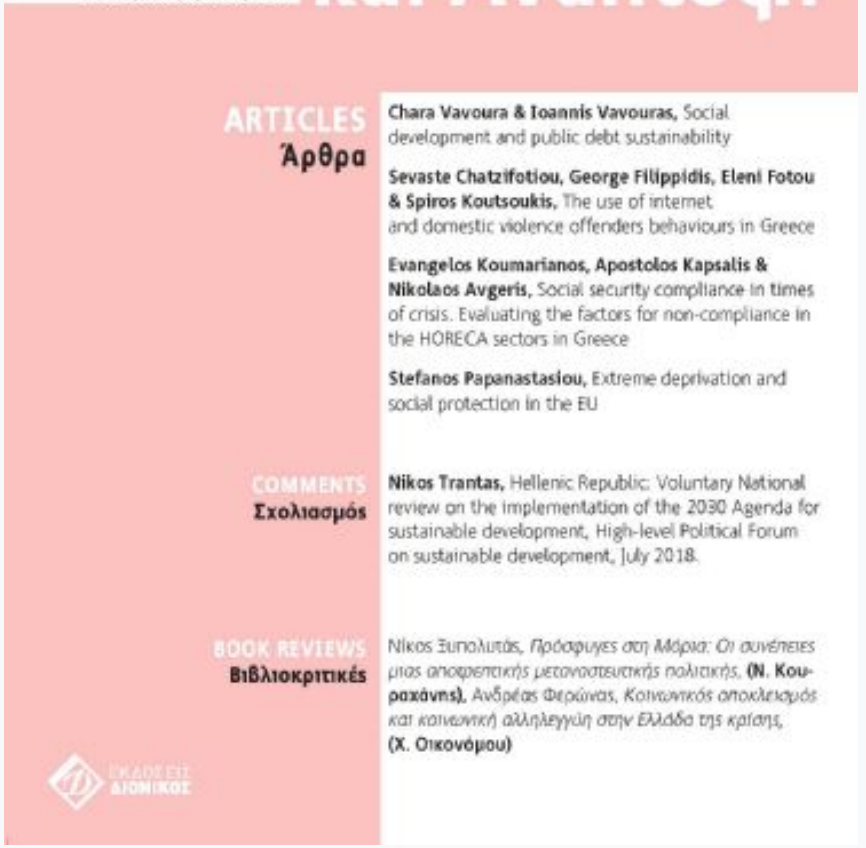

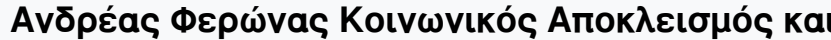

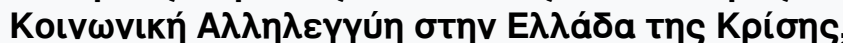
AӨńva: $\Delta$ เóvıкos, 2019

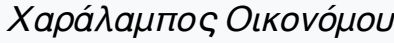

doi: $10.12681 /$ scad.25759

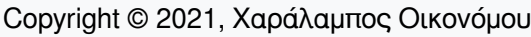

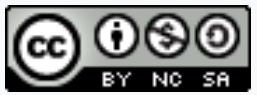

This work is licensed under a Creative Commons Attribution-NonCommercialShareAlike 4.0.

To cite this article:

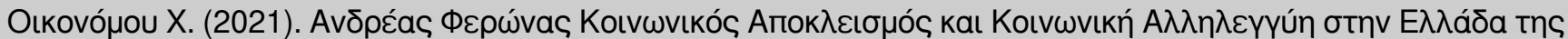
Kpíons, AӨńva: $\Delta$ ıóvikoc, 2019. Social Cohesion and Development, 14(2), 139-142.

https://doi.org/10.12681/scad.25759 


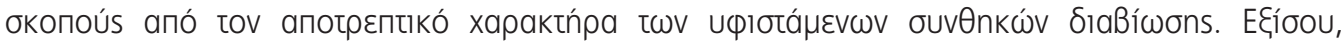

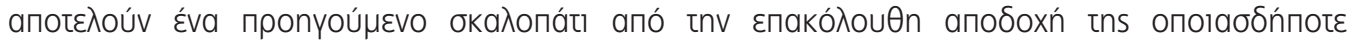

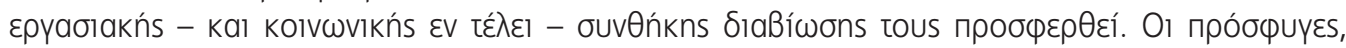

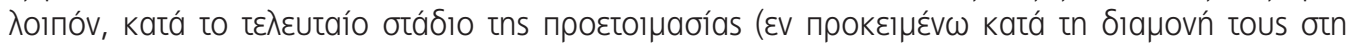

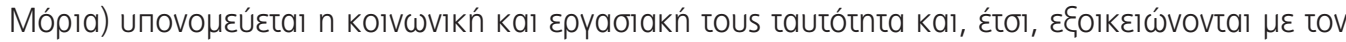

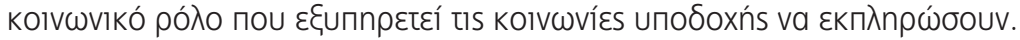

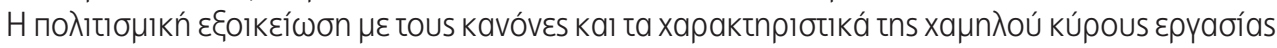

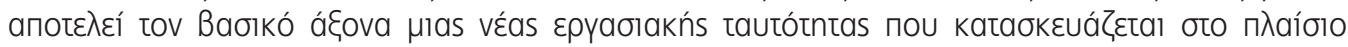

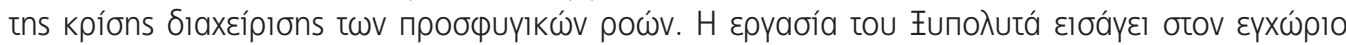

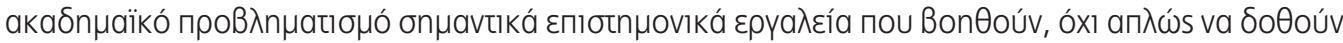

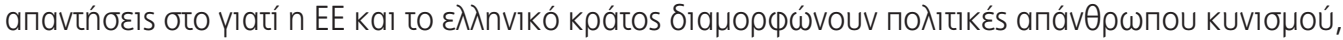

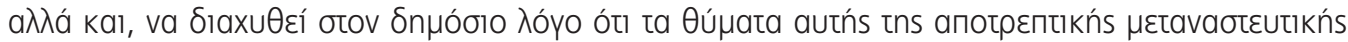

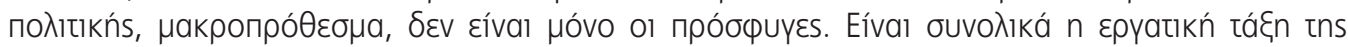

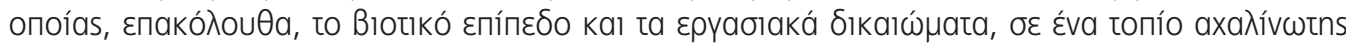

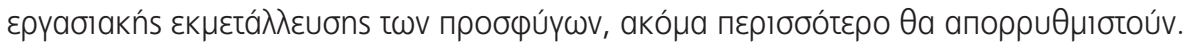

Níkos Koupaxávns,

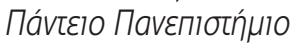

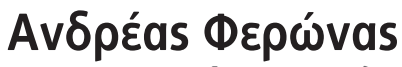

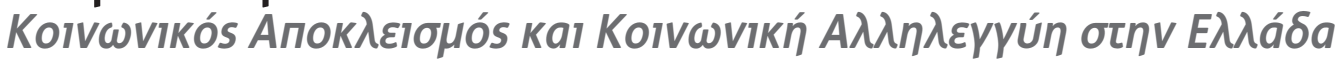

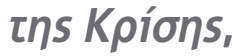 A日ńva: Alóvikos, 2019}

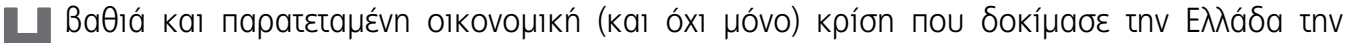

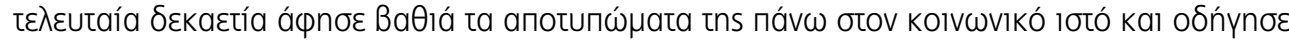

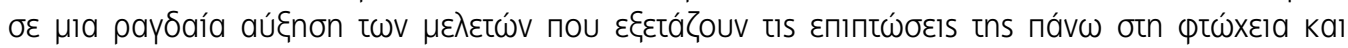

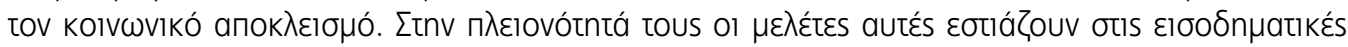

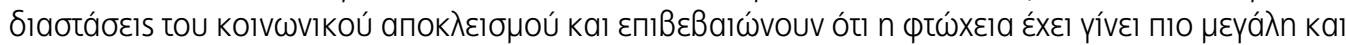

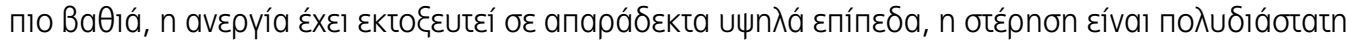

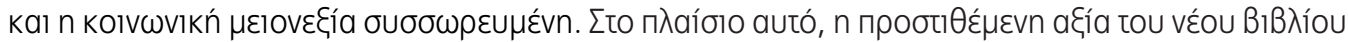

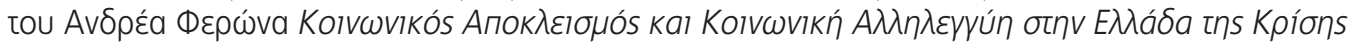

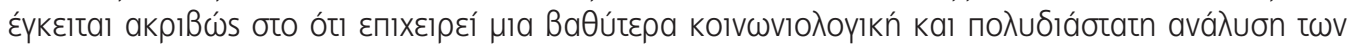

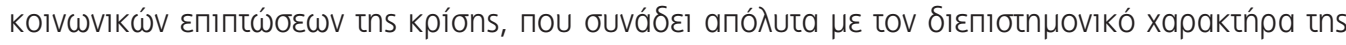

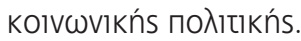

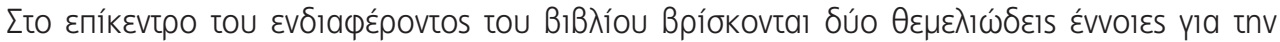

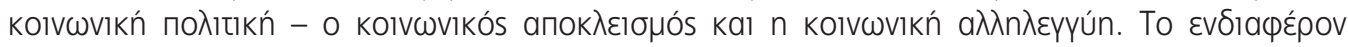

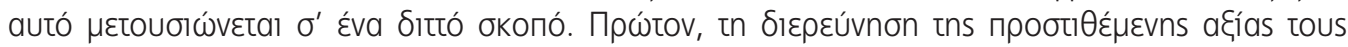

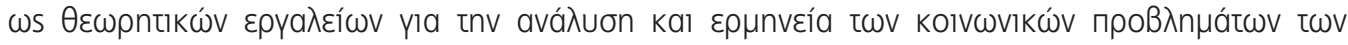

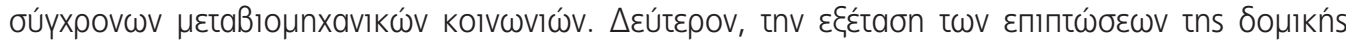

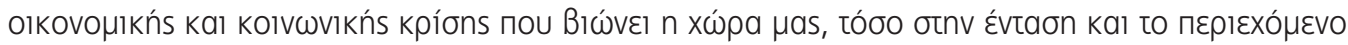




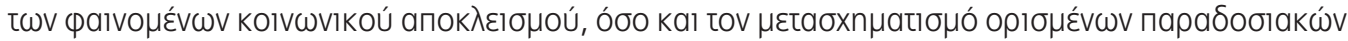

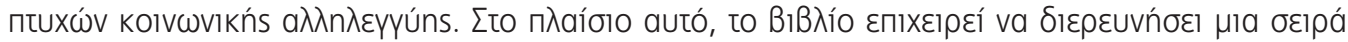

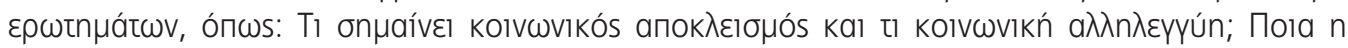

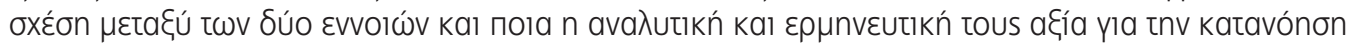

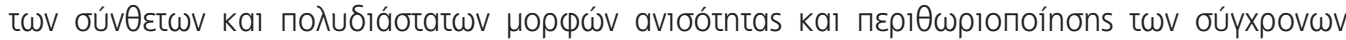

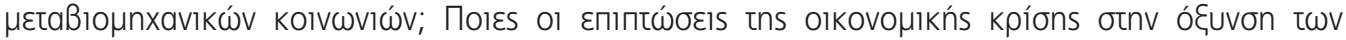

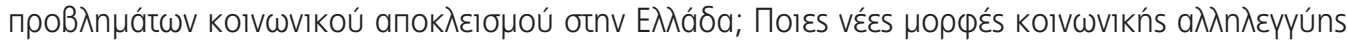

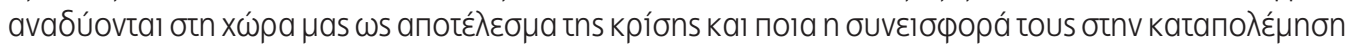

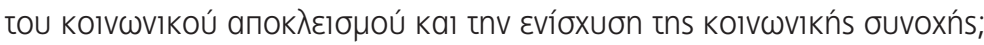

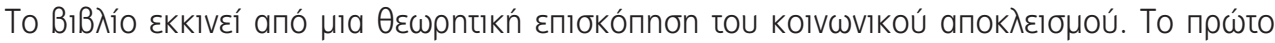

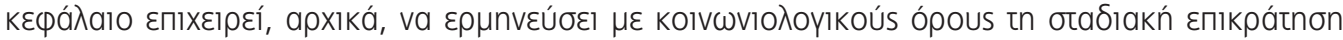

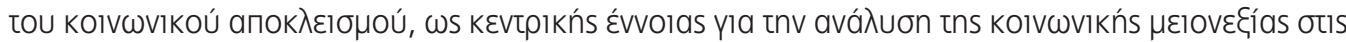

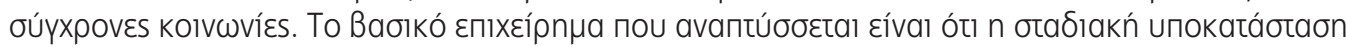

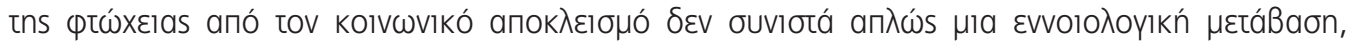

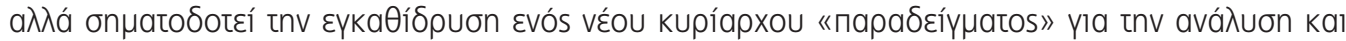

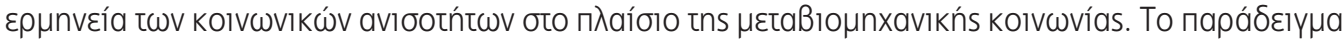

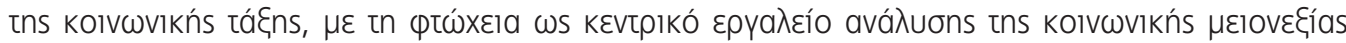

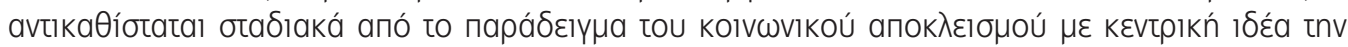

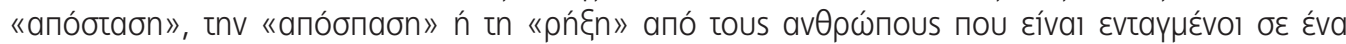

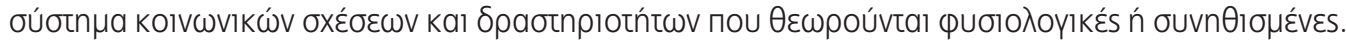

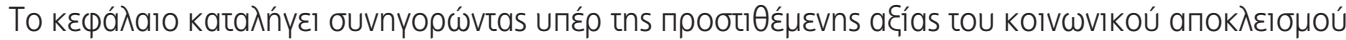

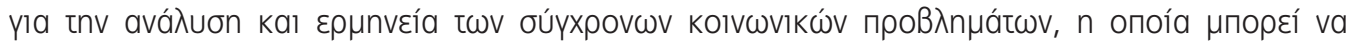

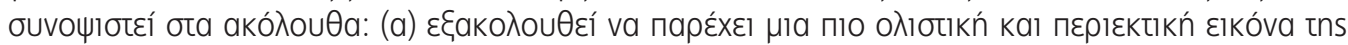

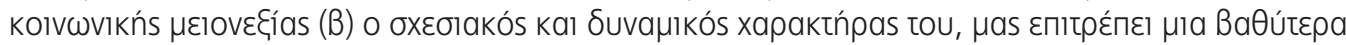

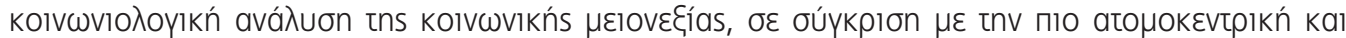

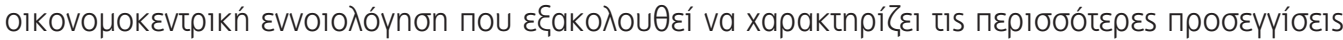

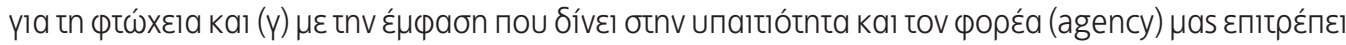

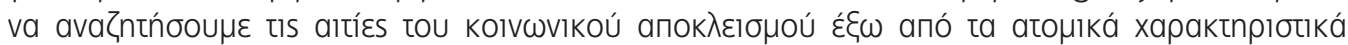

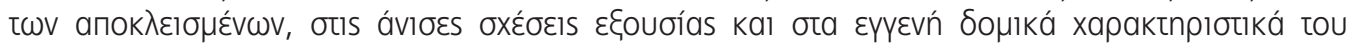

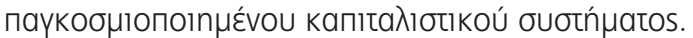

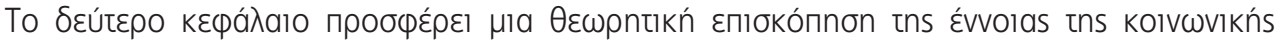

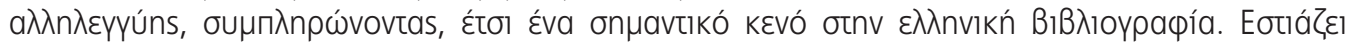

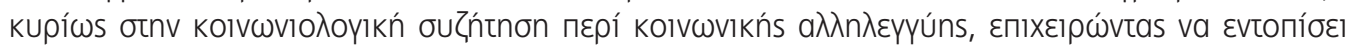

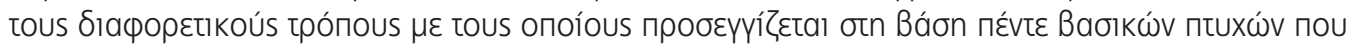

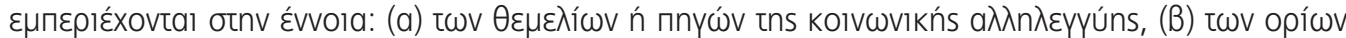

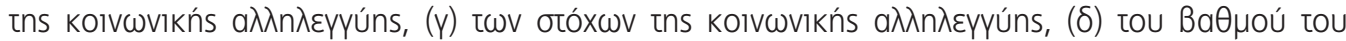

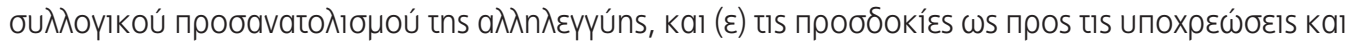

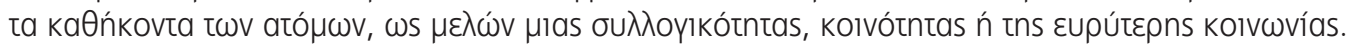

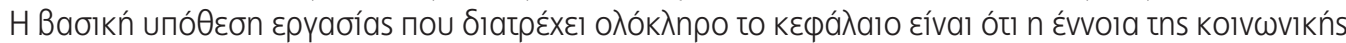

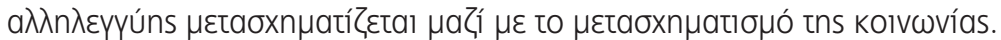

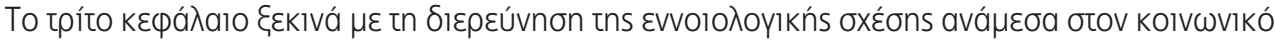

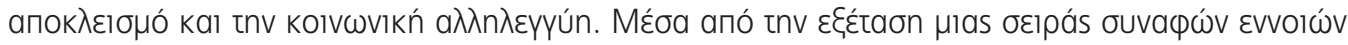

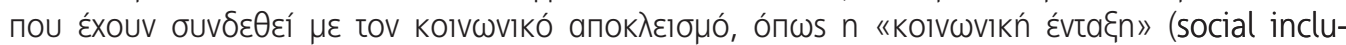

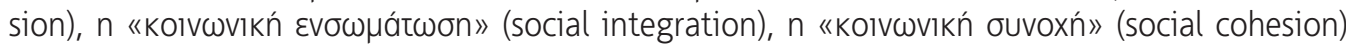




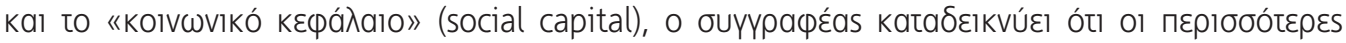

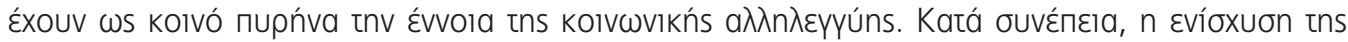

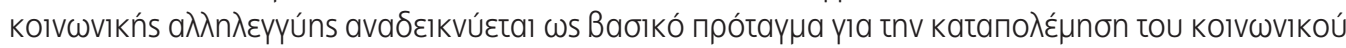

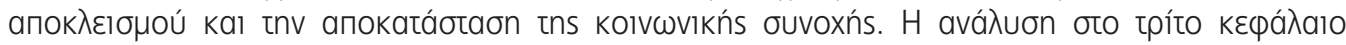

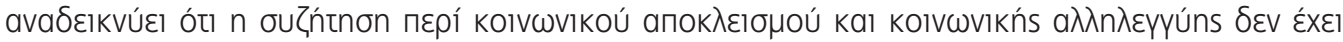

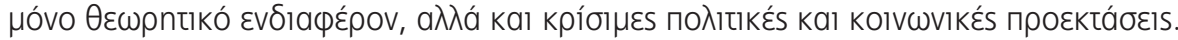

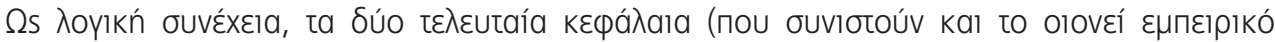

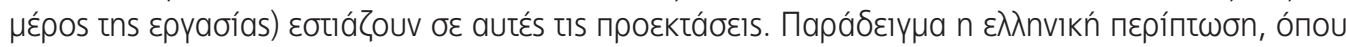

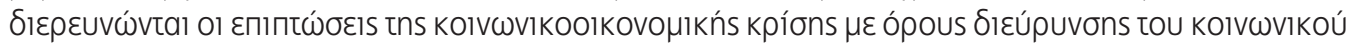

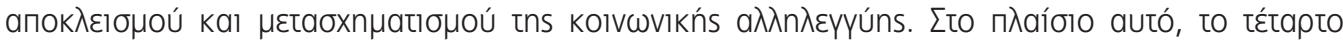

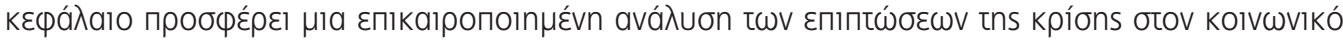

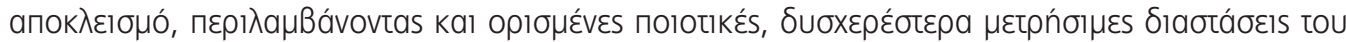

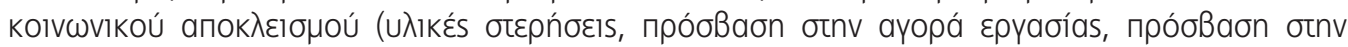

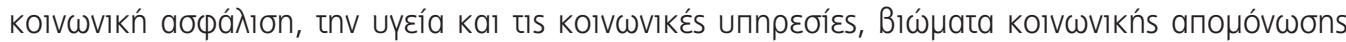

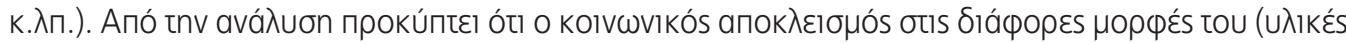

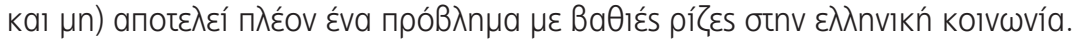

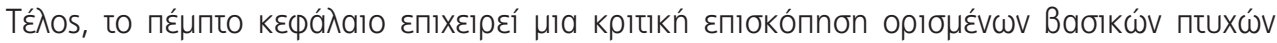

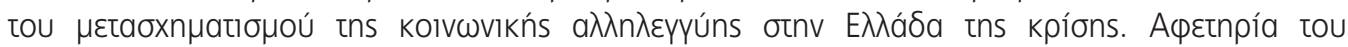

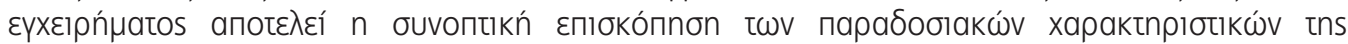

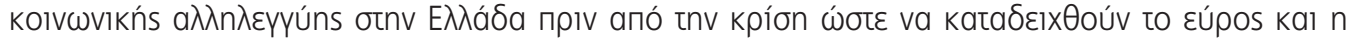

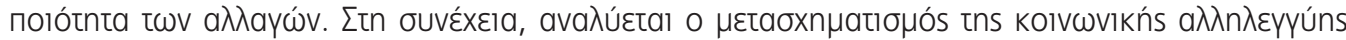

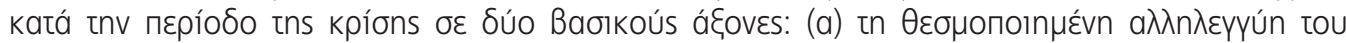

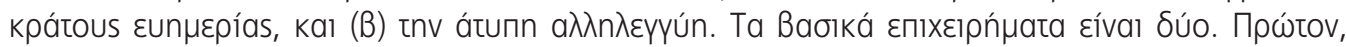

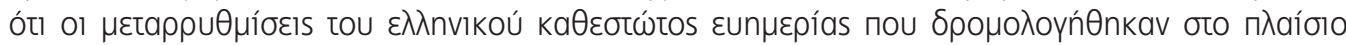

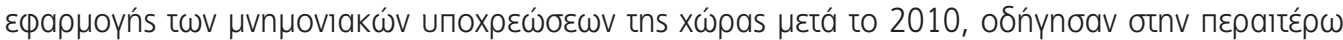

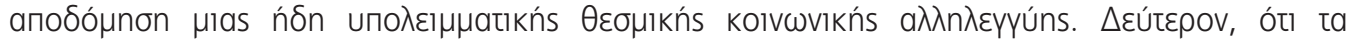

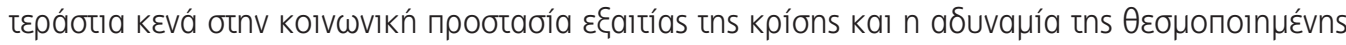

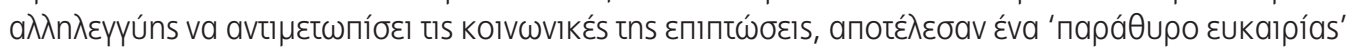

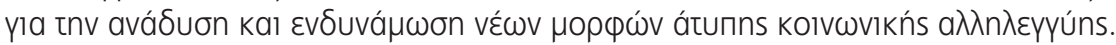

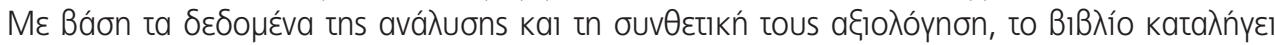

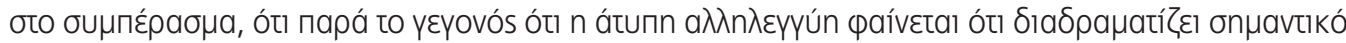

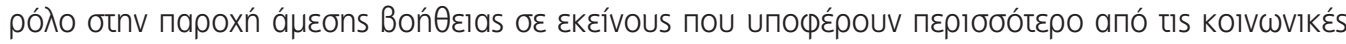

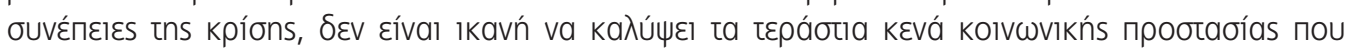

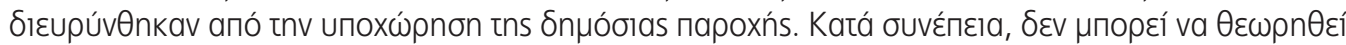

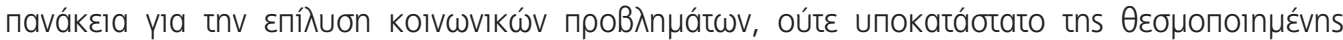

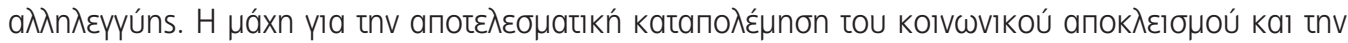

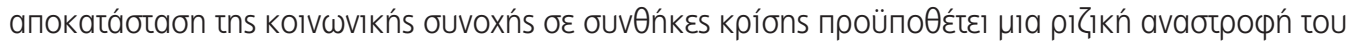

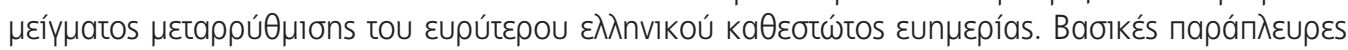

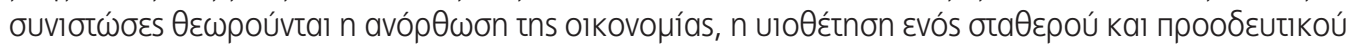

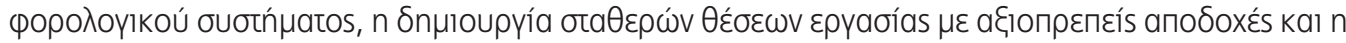

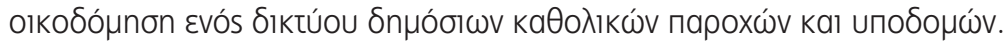

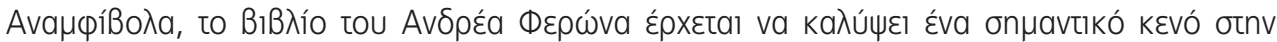

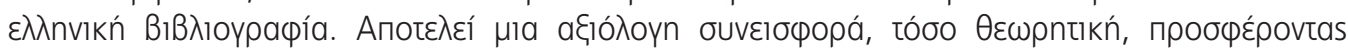

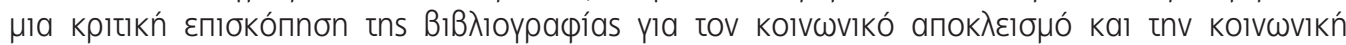




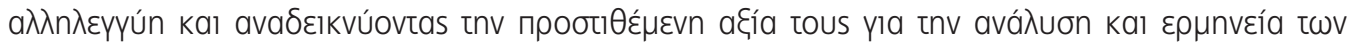

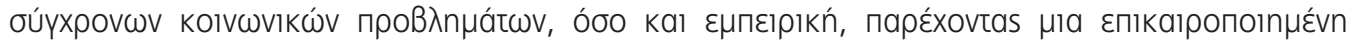

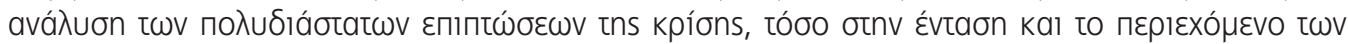

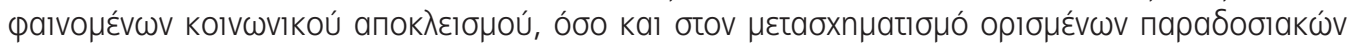

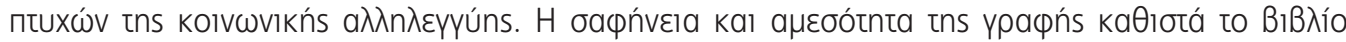

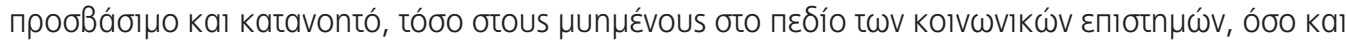

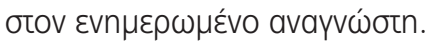

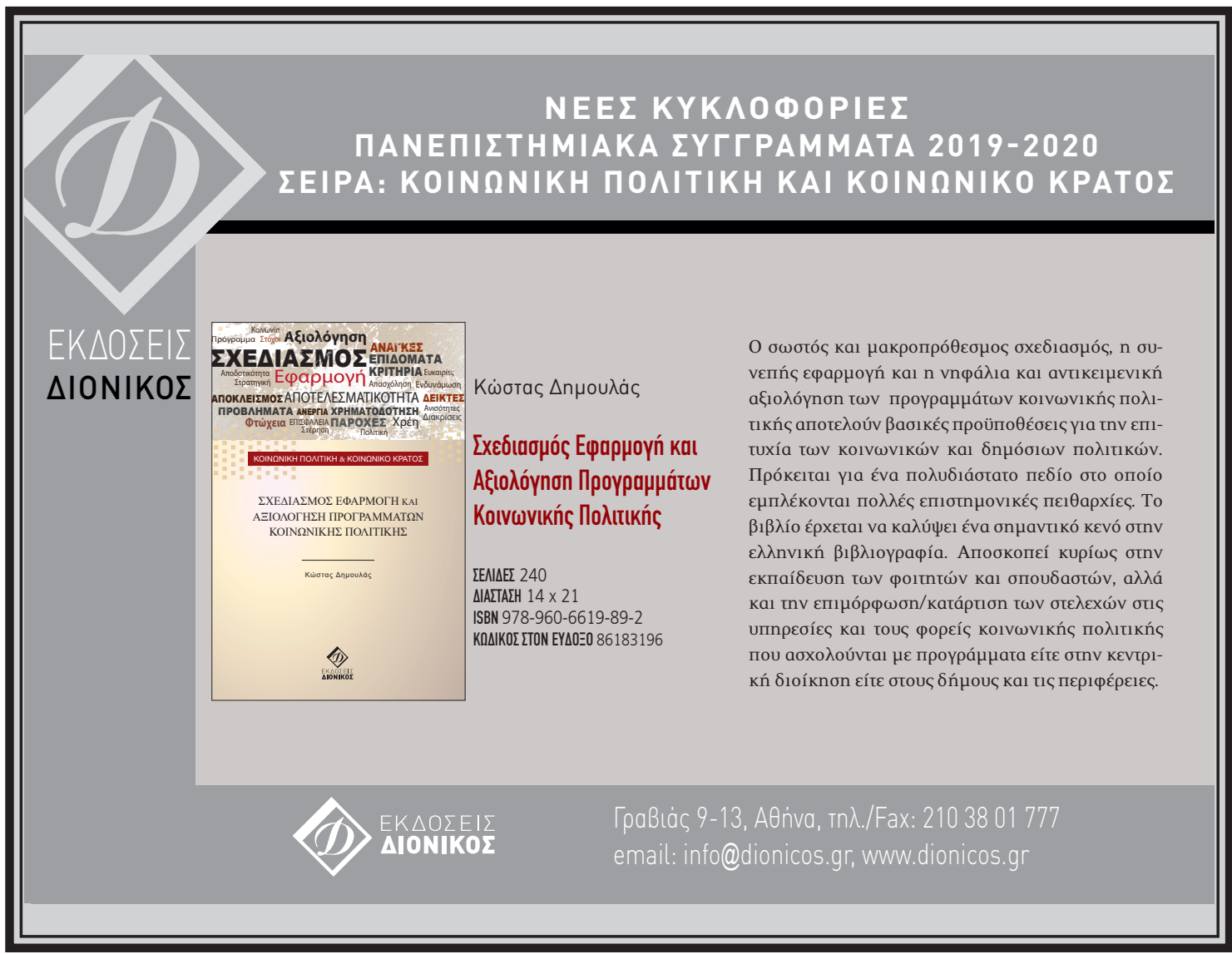

